\title{
Editorial
}

\section{The Origin of the Effective Treatment of Cardiac Shock}

\author{
Myron Prinzmetal, M.D.*
}

$\mathrm{HE}$ author became interested in shock-like states in 1943 while working
on wound shock. ${ }^{1-10}$ )

At that time, it will be recalled, thcre was no effective treatment for cardiac shock. The mortality rate was almost universal. Cardiac shock and its accompanying low blood pressure were considered to be a homeostatic mechanism to relieve the work of the heart. ${ }^{11-14)}$

In 1946, in the author's laboratory, experiments with radioactive isotopes were performed on dogs. The radioactive isotopes were provided by the late Nobel Prize laureate, Dr. Ernest Lawrence. Red blood cells were made radioactive. It was clearly demonstrated that the blood flow to the heart and other essential organs was impaired in all shock-like states.

Through the use of drugs which effectively raised blood pressure, it was clearly demonstrated that as the blood pressure was raised, the blood flow to the heart and other essential organs was greatly improved. Some of the drugs used were Paredrine, obtained from the late Gordon Alles, Ph.D., and Neosynephrine.

Following this fundamental contribution, the author applied this knowledge to patients in cardiogenic shock. It was immediately found that many patients doomed to die, were saved.

The author presented this material June 6, 1947, at the American Heart Association meeting in Atlantic City, New Jersey, and at several other national and international meetings.

Drugs and treatment have improved since this original demonstration. It is most likely that newer and better drugs will be found-further lowering the mortality rate-based on the fundamental observation made so many years ago.

\footnotetext{
* Clinical Professor of Medicine, University of California Medical Center, Los Angeles; Senior Attending Physician at Cedars-Sinai Medical Center, Cedars of Lebanon Hospital, Los Angeles; and Chief Cardiologist at the City of Hope Medical Center, Duarte, California.

Received for publication July 22, 1965.
} 


\section{AGKNOWLEDGEMENT}

The author wishes to thank Mr. John Connor, librarian of the Los Angeles County Medical Association, and Dr. Chauncey D. Leake of the University of California Medical Center, San Francisco, the author's old and dear friend and teacher, for their bibliographic assistance and advice.

\section{REFERENCES}

1. Prinzmetal, M. et al.: War Medicine 5: 74, 1944.

2. Prinzmetal, M. et al.: Surgery 16: 914, 1944.

3. Bergman, H. C. and Prinzmetal, M.: Arch. Surg. 50: 201, 1945.

4. Prinzmetal, M. and Bergman, H. C.: J. Mt. Sinai Hosp. 12: 579, 1945.

5. Prinzmetal, M. et al.: Am. J. Med. Sci. 211 : 590, 1946.

6. Bergman, H. C. and Prinzmetal, M. : J. Lab. Clin. Med. 31: 654, 1946.

7. Bergman, H. C. and Prinzmetal, M.: J. Lab. Clin. Med. 31:663, 1946.

8. Prinzmetal, M. et al.: Am J. Physiol. 146: 366, 1946.

9. Prinzmetal, M. et al. : Am. Heart J. 33 : 420, 1947.

10. Kruger, H. E. and Prinzmetal, M.: J. Lab. Clin. Med. 33: 502, 1948.

11. Master, A. M. et al.: Am. Heart J. 27: 803, 1944.

12. Gilbert, N. C.: Med. Clin. North. Amer. 28 : 1, 1944.

13. Stroud, W. D.: Diagnosis and Treatment of Cardiovascular Disease, vol. 1, F. A. Cavis Co., Philadelphia, p. 499, 1945.

14. Prinzmetal, M.: Studies in Coronary Circulation (undistributed film, silent, 30 min., 1946). 